\title{
Risk factors for childhood overweight: a 30-month longitudinal study of 3- to 6-year-old children
}

\author{
Valerie De Coen ${ }^{1, *}$, Ilse De Bourdeaudhuii ${ }^{2}$, Vera Verbestel ${ }^{2}$, Lea Maes ${ }^{1}$ and \\ Carine Vereecken ${ }^{1,3}$ \\ ${ }^{1}$ Faculty of Medicine and Health Sciences, Department of Public Health, Ghent University, De Pintelaan 185, \\ B-9000 Ghent, Belgium: ${ }^{2}$ Faculty of Medicine and Health Sciences, Department of Movement and \\ Sport Sciences, Ghent University, Ghent, Belgium: ${ }^{3}$ Research Foundation Flanders, Brussels, Belgium
}

Submitted 20 February 2013: Final revision received 14 June 2013: Accepted 25 July 2013: First published online 4 September 2013

\begin{abstract}
Objective: The increasing prevalence of childhood overweight is an important health issue. There is a need for longitudinal research among children in order to identify risk factors for childhood overweight. The objective of the present research was to identify potential sociodemographic and behavioural risk factors for development of childhood overweight among 3- to 6-year-old children.

Design: Longitudinal study.

Setting: Sixteen pre-primary and primary schools.

Subjects: BMI Z-scores at baseline and two follow-up measurements were calculated for 568 children. Sociodemographic, parental adiposity, familial composition, child's diet, physical activity and sedentary behavioural data were collected through questionnaires.

Results: Several risk factors for the development of childhood overweight were found. Being an only child, lower maternal educational level, maternal and paternal overweight, more than $1 \mathrm{~h}$ screen time on weekdays and high soft drinks consumption were shown to be positively associated with the development of childhood overweight.

Conclusions: Although behavioural factors are important, our findings support the thesis that interventions on the prevention of childhood overweight should focus on high-risk groups, i.e. children from low socio-economic background or with high parental BMI. Interventions should address the whole family and take into account their lifestyle and structure.
\end{abstract}

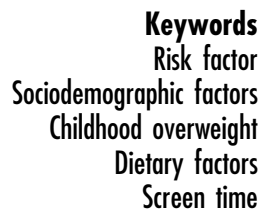

The dramatically increasing prevalence of childhood overweight worldwide is an important health issue ${ }^{(1,2)}$. Overweight children face health risks such as increased blood pressure ${ }^{(3)}$, diabetes ${ }^{(4)}$ and a decreased life quality ${ }^{(5)}$, as well as risks for adult health ${ }^{(6)}$. Understanding the relationship between childhood overweight and its risk factors can aid the development of interventions on prevention of childhood overweight. Childhood overweight is multifactorial, caused by an imbalance between energy intake and expenditure, and has a genetic and environmental interaction $^{(7,8)}$. For pre-school and school children, a number of factors underlying childhood overweight have been found, both on the environmental and behavioural domains. The first level of factors includes the genetic and social predisposition of the child. A second level of factors consists of the child's dietary behaviour, physical activity level and sedentary behaviour. At a third level, the factors related to the obesogenic environment can be found.

Previous longitudinal studies have tried to reveal risk factors for childhood overweight for pre-primary and primary-school children, more specifically those aged 3 to 10 years. Parental overweight was the most important risk factor due to the combination of genes and environmental factors ${ }^{(7,9-13)}$. Hui et al. $^{(14)}$ and Scaglioni ${ }^{(15)}$, for example, found that children of overweight parents had a higher risk for overweight. Next to parental overweight, socio-economic status (SES) has been identified several times as a risk factor for childhood overweight ${ }^{(15-19)}$. Income, paternal/maternal employment and paternal/ maternal educational level are often used as indicators of SES. Wijga et al. ${ }^{(20)}$ found children of mothers with a low education to be at a higher risk for childhood overweight and Anderson et al. ${ }^{(21)}$ found that a child is more likely to be overweight if the mother worked more hours per week. However, most studies limit the indicators of SES to one or two variables ${ }^{(16,22)}$.

Parental overweight and sociodemographic variables are important but not easily susceptible to change. To prevent childhood overweight changeable behavioural risk factors must also be identified. Several studies have 
revealed dietary, physical activity (PA) and sedentary risk factors for childhood overweight. Soft drinks consumption is a possible risk factor for childhood overweight and related health problems ${ }^{(23,24)}$. Welsh et al.'s ${ }^{(25)}$ longitudinal study among 2- to 3-year-old children showed that soft drinks consumption was related to the risk of being overweight. In their review of longitudinal studies of dietary risk factors for development of childhood obesity, Moreno and Rodriguez ${ }^{(26)}$ found a consistent positive relationship between sugar-sweetened beverage consumption and obesity development. Field $e t a l^{(27)}$ found snack consumption not to be a risk factor for weight gain and Wijga et al. ${ }^{(20)}$ found it to be inversely associated with the child's weight status.

Epstein et al. ${ }^{(28)}$ found fewer overweight children in the group consuming more fruit and vegetables. The study by the US Department of Agriculture's Economic Research Service found a higher fruit consumption to be associated with a lower BMI for children ${ }^{(29)}$. Field et al. ${ }^{(30)}$ showed that vegetable intake was inversely related to BMI $Z$-score change if not controlled for energy intake. However, the association of fruit and vegetable intake to weight gain is not yet well understood ${ }^{(30)}$. Other healthy promoted food products are milk products due to their $\mathrm{Ca}$ content; Skinner et al. ${ }^{(31)}$ confirmed the inverse relationship between $\mathrm{Ca}$ intake and the child's weight status.

PA and sedentary behaviour also have a key role in the prevalence and development of overweight. The reviews by Jimenez-Pavon et al. ${ }^{(32)}$ and Must and Tybor ${ }^{(33)}$ showed an inverse relationship between PA and childhood overweight. Several longitudinal studies confirmed this significant relationship ${ }^{(34,35)}$. Sedentary behaviour induces a reduction in energy requirements. Screen time, a specific sedentary behaviour that includes watching television (TV) and playing video and computer games, has been found to be positively related with childhood overweight in several longitudinal studies: Jago et al. ${ }^{(36)}$ found that TV viewing was a significant predictor of BMI of 3- to 6-year-old children and Hesketh et al. ${ }^{(37)}$ found screen time to be an overweight risk factor for children aged 5 to 10 years.

The aim of the present longitudinal study was to assess significant risk factors on the familial, sociodemographic and behavioural domains for the development of childhood overweight in 3- to 6-year-old children.

\section{Methods}

\section{Study design}

The present study is a part of a project approved by the ethical committee of Ghent University (EC/2007/570). This project, the POP-project (Prevention of Overweight among Pre-school and school children), was conducted in six towns and municipalities in Belgium-Flanders as part of the Flemish Policy Research Centre for Welfare,
Health and Family and commissioned by the responsible minister. These six towns and municipalities were selected for an intervention study from the research regions in Flanders as decided by the Flemish Policy Research Centre.

Longitudinal data analyses reported in the present study used data from control condition municipalities. The municipalities' population ranged from 23000 to 50000 residents.

\section{Participants}

Recruitment of participants took place in schools. In Flanders, $98 \%$ of children attend pre-primary school (age 3 to 5 years) and at the age of 6 years, education at a primary school is compulsory. In the three municipalities, all pre-primary and primary schools were invited to participate. Participation was voluntary and sixteen of the twenty eligible schools participated (80\%). Within these schools, all pre-primary children (age 3 to 5 years) and those in the first year of primary school (age 6 years) were invited to participate in the study. Of the 1308 eligible children, 621 participated at baseline $(47 \cdot 5 \%)$. The baseline measurement took place in October of the school year 2008-2009; the follow-up measurements were conducted the following school years, in April 2010 and in April 2011.

Parents completed a questionnaire and height and weight of the children were measured. Parents provided a written consent at the start of the study that applied to the whole duration of the study.

The questionnaire used for the collection of sociodemographic and familial data, dietary behaviour, PA and sedentary behaviour was distributed by the teachers in the schools for parents to fill in. The questionnaire was returned to the teachers and collected by the research team. In some schools, parents experiencing language or other problems filling in the questionnaire were assisted by an intercultural worker or an interpreter.

\section{Measurements}

\section{$B M I$}

Height and weight of participating children, who were barefooted and in light clothing, were measured in the schools by the research team. Weight was measured to the nearest $0 \cdot 1 \mathrm{~kg}$ (Seca Robusta 813; Seca, Hamburg, Germany) and height to the nearest millimetre using a mobile stadiometer (Seca 214; Seca). Parental height and weight data were collected through the questionnaire. BMI $\left(\mathrm{kg} / \mathrm{m}^{2}\right)$ was computed and BMI $Z$-scores were calculated with Flemish reference data using the LMS (curve-L, mean-M and coefficient of variation-S method) ${ }^{(38,39)}$.

\section{Sociodemographic data}

Demographic factors were collected through the questionnaire: gender, date of birth, living situation (with both parents, with one parent, co-parenting, other), number of 
children in the family, language spoken at home, parental educational levels (primary school, lower secondary, higher secondary, higher education) and parental professional statuses (paid work, other).

\section{Dietary behaviour}

A validated semi-quantitative $\mathrm{FFQ}^{(40)}$ assessed quantities and frequencies of the consumption of the food groups water, soft drinks, milk and dairy products, vegetables, fruit and sweet and savoury snacks. Parents were asked to report consumption frequencies as (i) never or $<1 \mathrm{~d} /$ month, (ii) 1 to $3 \mathrm{~d} /$ month, (iii) $1 \mathrm{~d} /$ week, (iv) 2 to $4 \mathrm{~d} /$ week, (v) 5 to $6 \mathrm{~d} /$ week and (vi) every day; and the average consumption per day. The answering categories varied according to the food item and were expressed in grams or millilitres. The FFQ was previously validated in a sample of children, using estimated diet records of $3 \mathrm{~d}$ for 650 children aged 2.5-6.5 years. This previous validation study measured reproducibility ( $n$ 124) by repeated FFQ administrations five weeks apart. For most foods, a moderate level of relative validity (67-88\%) was observed for estimated food intake.

\section{Physical activity and sedentary behaviour}

The child's PA was calculated by assessing PA at home and structured PA. There are many instruments for assessing PA and parental self-report has been proved to be a valid, reliable instrument ${ }^{(41,42)}$. Parents were asked to report the time of $\mathrm{PA}$ at home. The six answer categories ranged from nil to $6 \mathrm{~h} / \mathrm{d}$. PA at home was converted to hours per week in accordance with structured PA.

To assess structured PA, parents were asked whether their child was a sports club member and for how many hours per week (nil if not a member). Second, they were asked whether their child participated in after-school sports activities and for how many hours per week (nil if not a member). Structured PA was calculated by adding the time in a sports club and in after-school sports activities.

For screen time, parents filled in the average daily time the child spent in front of the TV, computer, watching DVD, etc. during weekdays and weekend days separately. The six answer categories ranged from nil to $6 \mathrm{~h} / \mathrm{d}$.

\section{Statistical analyses}

Data were analysed using the statistical software package SPSS/PC version 19.0 for Windows. Means and standard deviations were calculated for all variables. Independentsamples $t$ tests and $\chi^{2}$ analyses were performed to assess the differences in characteristics between the drop-out groups and the baseline participants.

Clustering at the school level was considered; however, multilevel analyses were not needed as the variance explained was less than $5 \%$. Baseline underweight participants ( $n$ 53) were not included for further analyses due to their favourability of weight gain. The cut-off point for underweight was chosen as BMI $Z$-score $=-1^{(43)}$.
Missing data were handled using Multiple Imputation based on five imputed data sets. The imputed variables were: living situation, number of children in the family, maternal educational level, paternal educational level, language spoken at home, maternal professional status, paternal professional status, soft drinks consumption, water consumption, milk products consumption, fruit consumption, vegetable consumption, sweet and savoury snacks consumption, PA at home, structured PA, screen time on weekdays and screen time on weekend days. Missing data ranged from $3.6 \%$ for language spoken at home to $25 \cdot 6 \%$ for maternal education.

Logistic regression analyses were performed to reveal the risk factors of being overweight on the two follow-up measurements. In the first model, all variables (sociodemographic and behavioural) were included in the regression model. For the relevance of prevention and the development of interventions, the second model only included changeable behavioural variables. All analyses were controlled for the child's baseline weight status. The cut-off point for overweight was BMI $Z$-score of $1^{(43)}$. For the dummy coding of parental BMI, the cut-off point of $25 \mathrm{~kg} / \mathrm{m}^{2}$ was chosen, the adult criterion for overweight. The familial living situation was divided into 'living with both parents' and 'other'. The number of children in the family was reconverted into ' 1 ' (no siblings) and ' $>1$ ' (siblings). The educational level of both parents was recoded into ' $\leq$ higher secondary education' ( $\leq 12$ years of education) and ' $\geq$ higher education' ( $\geq 12$ years of education). For language spoken at home, categories were 'Dutch' and 'other' (Dutch is the official language of Flanders, Belgium). For the professional status of the parents, we converted the answers into 'paid work' and 'other'.

For other variables the mean was chosen as the cut-off point for recoding. $P$ values $\leq 0.05$ were considered statistically significant, $P$ values $>0.05$ and $\leq 0.10$ as a trend for significance.

\section{Results}

\section{Characteristics of participants and drop-outs}

Baseline values are shown in Table 1. The average age of the participating children was 5 years (mean 4.95 (SD 1.29) years). At baseline, 19\% of the children were overweight, $5 \%$ became overweight during the 30-month study period; $26 \%$ of the mothers were overweight and $48 \%$ of the fathers were overweight at baseline. The mean paternal BMI was $25 \cdot 3(\mathrm{sD} 3.43) \mathrm{kg} / \mathrm{m}^{2}$, the mean maternal BMI was $23 \cdot 7$ (SD $4 \cdot 26) \mathrm{kg} / \mathrm{m}^{2}$. A great majority of the children lived with both parents (85\%) and spoke Dutch at home (94\%), $55 \%$ of the mothers and $46 \%$ of the fathers had a higher education, $86 \%$ of the mothers and $91 \%$ of the fathers had paid work as a professional status. The mean for soft drinks consumption was $65 \mathrm{ml} / \mathrm{d}$, for water consumption $286 \mathrm{ml} / \mathrm{d}$, for sweet and savoury 
Table 1 Participant characteristics at baseline; 3- to 6-year-old children ( $n$ 568), Flanders, Belgium, 2008-2009 school year

\begin{tabular}{|c|c|c|}
\hline Variable & Mean & SD \\
\hline Age (years) & 4.95 & $1 \cdot 29$ \\
\hline Sex (\% girls) & \multicolumn{2}{|c|}{$53 \cdot 1$} \\
\hline Living situation (\% living with both parents) & \multicolumn{2}{|c|}{$85 \cdot 4$} \\
\hline Number of children in the family & $2 \cdot 34$ & $1 \cdot 10$ \\
\hline Maternal educational level (\% with higher education) & \multicolumn{2}{|c|}{$54 \cdot 6$} \\
\hline Paternal educational level ( $\%$ with higher education) & \multicolumn{2}{|c|}{$46 \cdot 2$} \\
\hline Language spoken at home (\% Dutch) & \multicolumn{2}{|c|}{$93 \cdot 7$} \\
\hline Maternal professional status (\% in paid work) & \multicolumn{2}{|c|}{$86 \cdot 2$} \\
\hline Paternal professional status (\% in paid work) & \multicolumn{2}{|c|}{$91 \cdot 1$} \\
\hline Maternal overweight (\%) & \multirow{2}{*}{\multicolumn{2}{|c|}{$\begin{array}{l}26 \cdot 0 \\
47 \cdot 6\end{array}$}} \\
\hline Paternal overweight (\%) & & \\
\hline Maternal BMI $\left(\mathrm{kg} / \mathrm{m}^{2}\right)$ & $23 \cdot 7$ & $4 \cdot 26$ \\
\hline Paternal BMI $\left(\mathrm{kg} / \mathrm{m}^{2}\right)$ & $25 \cdot 3$ & $3 \cdot 43$ \\
\hline Soft drinks consumption $(\mathrm{ml} / \mathrm{d})$ & $65 \cdot 4$ & $98 \cdot 9$ \\
\hline Water consumption $(\mathrm{ml} / \mathrm{d})$ & 286 & 166 \\
\hline Milk products consumption (g/d) & 329 & 205 \\
\hline Fruit consumption $(\mathrm{g} / \mathrm{d})$ & 136 & $84 \cdot 7$ \\
\hline Vegetable consumption $(\mathrm{g} / \mathrm{d})$ & $71 \cdot 7$ & $58 \cdot 9$ \\
\hline Sweet and savoury snacks consumption (g/d) & $53 \cdot 7$ & $46 \cdot 3$ \\
\hline $\mathrm{PA}$ at home (h/week) & $5 \cdot 98$ & $2 \cdot 60$ \\
\hline Structured PA (h/week) & $4 \cdot 06$ & $4 \cdot 72$ \\
\hline Screen time on weekdays $(\mathrm{h} / \mathrm{d})$ & $1 \cdot 16$ & 0.94 \\
\hline Screen time on weekend days $(\mathrm{h} / \mathrm{d})$ & $2 \cdot 07$ & $1 \cdot 31$ \\
\hline BMI Z-score of child & $0 \cdot 14$ & 0.95 \\
\hline Child's weight status at baseline (\% overweight) & \multicolumn{2}{|c|}{$18 \cdot 6$} \\
\hline Children who developed overweight during the 30 -month follow-up (\%) & \multicolumn{2}{|c|}{$4 \cdot 7$} \\
\hline
\end{tabular}

PA, physical activity.

snacks $54 \mathrm{~g} / \mathrm{d}$, for milk products consumption $329 \mathrm{ml} / \mathrm{d}$, for fruit consumption $136 \mathrm{~g} / \mathrm{d}$ and for vegetable consumption $72 \mathrm{~g} / \mathrm{d}$. The mean for PA at home was $6 \mathrm{~h} /$ week, for structured PA $4 \mathrm{~h} /$ week. Mean screen time was $1 \mathrm{~h} / \mathrm{d}$ on weekdays and $2 \mathrm{~h} / \mathrm{d}$ on weekend days.

The characteristics of the drop-out groups are shown in Table 2. Significant differences between the 18-month drop-out group and participants were found for living situation: the drop-out group had fewer children living with both parents; and for maternal and paternal professional status: parents who dropped out at the first measurement had less paid work. The drop-out group at the 30-month measurement differed significantly from the participants on maternal and paternal educational level: the drop-outs had less higher education. They also differed on language spoken at home: they spoke more Dutch than the participants; and on maternal and paternal status: although their percentage in paid work was higher than the first drop-out group, it was still significantly lower than that of the participants. The second drop-out group also consumed significantly more soft drinks and less milk products.

\section{Predictors of overweight at 18- and 30-month follow-ups}

The results of the first model with sociodemographic and behavioural variables included are presented in Table 3 . Being an only child was a significant risk factor for childhood overweight (first follow-up: OR $=0 \cdot 48,95 \% \mathrm{CI}$ $0 \cdot 25,0 \cdot 94, P=0 \cdot 03$ ): children without siblings were more likely overweight at the first follow-up measurement compared with children with siblings. This was no longer significant at the second follow-up measurement. If the mother had no higher education, the child had double the chance of being overweight at the second follow-up measurement compared with children of mothers with a higher education (second follow-up: $\mathrm{OR}=0 \cdot 51,95 \% \mathrm{CI}$ $0 \cdot 25,1 \cdot 08, P=0 \cdot 058)$. Maternal weight status was a significant risk factor on both measurements (first follow-up: $\mathrm{OR}=2 \cdot 62,95 \%$ CI $1 \cdot 46,4 \cdot 69, P=0 \cdot 002$; second followup: $\mathrm{OR}=2 \cdot 99,95 \%$ CI $1 \cdot 80,4 \cdot 9, P<0 \cdot 001)$ : children of an overweight mother had more chance of being overweight at both follow-up measurements. Paternal weight status was also a risk factor for childhood overweight on both measurements: children with an overweight father had more chance of being overweight at the follow-up measurements (first follow-up: $\mathrm{OR}=2 \cdot 16,95 \% \mathrm{CI} 1 \cdot 21$, $3 \cdot 86, P=0 \cdot 01$; second follow-up: $\mathrm{OR}=2 \cdot 01,95 \%$ CI $0 \cdot 97,4 \cdot 25, P=0 \cdot 06$ ). Children with more than $1 \mathrm{~h}$ screen time on weekdays had more chance of being overweight on both follow-up measurements (first follow-up: OR = $1.91,95 \%$ CI $0.91,3 \cdot 06, P=0 \cdot 08$; second follow-up: $\mathrm{OR}=2 \cdot 07,95 \% \mathrm{CI} 0 \cdot 98,4 \cdot 25, P=0 \cdot 06$ ). These analyses were controlled for the child's baseline weight status. The results showed that this was a significant predictor of being overweight: children who were already overweight at baseline had fifty-seven times more chance of being overweight at the first follow-up and thirty-four times more chance of being overweight at the second follow-up measurement (first follow-up: OR $=57 \cdot 4,95 \%$ CI $28 \cdot 1$, 
Table 2 Baseline characteristics of the participants who dropped out at the 18-month and 30-month follow-ups; 3- to 6-year-old children ( $n$ 568), Flanders, Belgium (baseline 2008-2009 school year; first follow-up conducted in April 2010; second follow-up conducted in April 2011)

\begin{tabular}{|c|c|c|c|c|}
\hline \multirow[b]{2}{*}{ Variable } & \multicolumn{2}{|c|}{$\begin{array}{l}\text { 18-month follow-up } \\
\text { drop-out group ( } n \text { 222) }\end{array}$} & \multicolumn{2}{|c|}{$\begin{array}{l}\text { 30-month follow-up } \\
\text { drop-out group ( } n \text { 90) }\end{array}$} \\
\hline & Mean & SD & Mean & SD \\
\hline Age (years) & 4.92 & $1 \cdot 27$ & $5 \cdot 11$ & $1 \cdot 17$ \\
\hline Sex (\% girls) & \multirow{2}{*}{\multicolumn{2}{|c|}{$\begin{array}{l}51 \cdot 4 \\
80 \cdot 1+\end{array}$}} & \multicolumn{2}{|c|}{$48 \cdot 8$} \\
\hline Living situation (\% living with both parents) & & & & \\
\hline Number of children in the family & $2 \cdot 48$ & $1 \cdot 16$ & $2 \cdot 31$ & $1 \cdot 21$ \\
\hline Maternal educational level (\% with higher education) & \multicolumn{2}{|c|}{$52 \cdot 1$} & \multicolumn{2}{|c|}{$47 \cdot 9+$} \\
\hline Paternal educational level (\% with higher education) & \multicolumn{2}{|c|}{$47 \cdot 4$} & \multicolumn{2}{|c|}{$38 \cdot 8+$} \\
\hline Language spoken at home (\% Dutch) & \multirow{2}{*}{\multicolumn{2}{|c|}{$\begin{array}{l}93 \cdot 1 \\
62.7 t\end{array}$}} & \multicolumn{2}{|c|}{$96 \cdot 5+$} \\
\hline Maternal professional status (\% in paid work) & & & \multicolumn{2}{|c|}{$77 \cdot 2 \dagger$} \\
\hline Paternal professional status (\% in paid work) & \multicolumn{2}{|c|}{$\begin{array}{l}62 \cdot 7 \dagger \\
82 \cdot 4 t\end{array}$} & \multicolumn{2}{|c|}{$76 \cdot 4+$} \\
\hline Maternal overweight (\%) & \multirow{2}{*}{\multicolumn{2}{|c|}{$\begin{array}{l}31 \cdot 6 \\
48.6\end{array}$}} & \multirow{2}{*}{\multicolumn{2}{|c|}{$\begin{array}{l}30 \cdot 0 \\
48 \cdot 7\end{array}$}} \\
\hline Paternal overweight (\%) & & & & \\
\hline Maternal BMI $\left(\mathrm{kg} / \mathrm{m}^{2}\right)$ & $23 \cdot 7$ & $4 \cdot 39$ & $23 \cdot 6$ & $4 \cdot 41$ \\
\hline Paternal BMI $\left(\mathrm{kg} / \mathrm{m}^{2}\right)$ & $25 \cdot 5$ & 3.62 & $25 \cdot 2$ & 3.63 \\
\hline Soft drinks consumption $(\mathrm{ml} / \mathrm{d})$ & $66 \cdot 5$ & $96 \cdot 1$ & $78 \cdot 8+$ & 117 \\
\hline Water consumption $(\mathrm{ml} / \mathrm{d})$ & 276 & 161 & 266 & 157 \\
\hline Milk products consumption ( $\mathrm{g} / \mathrm{d})$ & 320 & 201 & $304+$ & 201 \\
\hline Fruit consumption $(\mathrm{g} / \mathrm{d})$ & 137 & $89 \cdot 3$ & 132 & $88 \cdot 7$ \\
\hline Vegetable consumption $(\mathrm{g} / \mathrm{d})$ & $71 \cdot 2$ & $66 \cdot 5$ & $65 \cdot 5$ & $46 \cdot 0$ \\
\hline Sweet and savoury snacks consumption (g/d) & $49 \cdot 9$ & $33 \cdot 1$ & $50 \cdot 8$ & $23 \cdot 8$ \\
\hline PA at home (h/week) & $6 \cdot 25$ & $2 \cdot 61$ & $6 \cdot 53$ & $2 \cdot 70$ \\
\hline Structured PA (h/week) & 3.97 & $4 \cdot 81$ & $3 \cdot 82$ & $3 \cdot 16$ \\
\hline Screen time on weekdays $(\mathrm{h} / \mathrm{d})$ & $1 \cdot 22$ & $1 \cdot 01$ & $1 \cdot 19$ & 0.94 \\
\hline Screen time on weekend days $(\mathrm{h} / \mathrm{d})$ & $2 \cdot 15$ & $1 \cdot 31$ & $2 \cdot 16$ & $1 \cdot 31$ \\
\hline BMI Z-score of child & $0 \cdot 17$ & 1.01 & 0.08 & 0.90 \\
\hline Child's weight status at baseline (\% overweight) & \multicolumn{2}{|c|}{$22 \cdot 2$} & \multicolumn{2}{|c|}{$15 \cdot 7$} \\
\hline
\end{tabular}

PA, physical activity.

tValue was significantly different from that of the participants $(P \leq 0.05)$.

Table 3 Multiple logistic regression: association between all baseline risk factors and childhood overweight at the follow-up measurements, controlled for the baseline weight status; 3- to 6-year-old children ( $n$ 568), Flanders, Belgium (baseline $2008-2009$ school year; first followup conducted in April 2010; second follow-up conducted in April 2011)

\begin{tabular}{|c|c|c|c|c|}
\hline \multirow[b]{2}{*}{ Variable (reference category) } & \multicolumn{2}{|c|}{ 18-month follow-up ( $n$ 538) } & \multicolumn{2}{|c|}{ 30-month follow-up ( $n$ 473) } \\
\hline & OR & $95 \% \mathrm{Cl}$ & OR & $95 \% \mathrm{Cl}$ \\
\hline Child's weight status at baseline (overweight) & $57 \cdot 4^{\star \star \star}$ & $28 \cdot 1,117$ & $33 \cdot 6^{\star \star \star}$ & $15 \cdot 1,74 \cdot 8$ \\
\hline Living situation (with both parents) & 0.59 & $0.23,1.54$ & 0.51 & $0.17,1 \cdot 53$ \\
\hline Number of children in the family $(>1)$ & $0 \cdot 48^{\star}$ & $0.25,0.94$ & 0.60 & $0 \cdot 30,1 \cdot 20$ \\
\hline Maternal educational level (higher education) & 0.73 & $0 \cdot 37,1 \cdot 35$ & $0 \cdot 51^{(*)}$ & $0.25,1 \cdot 08$ \\
\hline Paternal educational level (higher education) & $0 \cdot 77$ & $0.41,1 \cdot 48$ & 0.75 & $0.40,1 \cdot 42$ \\
\hline Language spoken at home (Dutch) & 0.69 & $0 \cdot 16,2 \cdot 44$ & 0.63 & $0 \cdot 16,2 \cdot 52$ \\
\hline Maternal professional status (in paid work) & $1 \cdot 31$ & $0 \cdot 31,5 \cdot 12$ & $1 \cdot 49$ & $0 \cdot 24,9 \cdot 35$ \\
\hline Paternal professional status (in paid work) & 0.66 & $0 \cdot 25,1 \cdot 75$ & 0.65 & $0.15,2.87$ \\
\hline Maternal weight status (overweight) & $2 \cdot 62^{\star \star}$ & $1 \cdot 46,4 \cdot 69$ & $2 \cdot 99^{\star \star *}$ & $1 \cdot 80,4 \cdot 97$ \\
\hline Paternal weight status (overweight) & $2 \cdot 16^{\star \star}$ & $1 \cdot 21,3 \cdot 86$ & $2 \cdot 01^{(*)}$ & $0 \cdot 97,4 \cdot 16$ \\
\hline Soft drinks consumption (>65 ml/d) & $1 \cdot 45$ & $0 \cdot 85,2 \cdot 48$ & $1 \cdot 36$ & $0 \cdot 77,2 \cdot 40$ \\
\hline Water consumption $(>286 \mathrm{ml} / \mathrm{d})$ & $1 \cdot 14$ & $0.69,1.91$ & 0.98 & $0.58,1.64$ \\
\hline Milk products consumption (>329 ml/d) & 1.08 & $0 \cdot 62,1 \cdot 90$ & $1 \cdot 13$ & $0.67,1 \cdot 89$ \\
\hline Fruit consumption $(>136 \mathrm{~g} / \mathrm{d})$ & $1 \cdot 04$ & $0 \cdot 61,1 \cdot 77$ & 0.98 & $0.48,1 \cdot 38$ \\
\hline Vegetable consumption (>72 g/d) & 0.99 & $0 \cdot 48,2 \cdot 04$ & $1 \cdot 23$ & $0 \cdot 63,2 \cdot 37$ \\
\hline Sweet and savoury snacks consumption ( $>54 \mathrm{~g} / \mathrm{d}$ ) & 0.92 & $0 \cdot 49,1 \cdot 73$ & $0 \cdot 70$ & $0 \cdot 35,1 \cdot 39$ \\
\hline $\mathrm{PA}$ at home (>6h/week) & $1 \cdot 10$ & $0 \cdot 66,1 \cdot 84$ & 0.82 & $0.49,1 \cdot 38$ \\
\hline Structured PA (>4h/week) & $0 \cdot 78$ & $0 \cdot 20,3 \cdot 01$ & $1 \cdot 03$ & $0 \cdot 38,2 \cdot 76$ \\
\hline Screen time on weekdays $(>1 \mathrm{~h} / \mathrm{d})$ & $1 \cdot 91^{(*)}$ & $0.91,3.06$ & $2 \cdot 07^{(*)}$ & $0.98,4 \cdot 25$ \\
\hline Screen time on weekend days $(>2 \mathrm{~h} / \mathrm{d})$ & $1 \cdot 07$ & $0 \cdot 49,2 \cdot 34$ & 1.00 & $0.39,2.56$ \\
\hline
\end{tabular}

PA, physical activity.

${ }^{(*)} P \leq 0 \cdot 1,{ }^{\star} P \leq 0.05,{ }^{* *} P \leq 0.01,{ }^{* *} P \leq 0.001$.

117, $P<0 \cdot 001$; second follow-up: $\mathrm{OR}=33 \cdot 6,95 \% \mathrm{CI}$

$15 \cdot 1,74 \cdot 8, P<0 \cdot 001)$

The multivariate logistic regression analyses were repeated with only changeable behavioural variables in the model and controlled for the baseline weight status of the child (first follow-up: $\mathrm{OR}=55 \cdot 0,95 \%$ CI 26.9, 112, $P<0 \cdot 001$; second follow-up: $\mathrm{OR}=31 \cdot 3, \quad 95 \%$ CI $15 \cdot 2, \quad 64 \cdot 4$, $P<0 \cdot 001)$. These results are shown in Table 4 and reveal 
Table 4 Multiple logistic regression: association between behavioural baseline risk factors and childhood overweight at the follow-up measurements, controlled for baseline weight status; 3- to 6-year-old children ( $n$ 568), Flanders, Belgium (baseline 2008-2009 school year; first follow-up conducted in April 2010; second follow-up conducted in April 2011)

\begin{tabular}{|c|c|c|c|c|}
\hline \multirow[b]{2}{*}{ Variable (reference category) } & \multicolumn{2}{|c|}{ 18-month follow-up ( $n$ 538) } & \multicolumn{2}{|c|}{ 30-month follow-up ( $n$ 473) } \\
\hline & OR & $95 \% \mathrm{Cl}$ & OR & $95 \% \mathrm{Cl}$ \\
\hline Child's weight status at baseline (overweight) & $55 \cdot 0^{\star * *}$ & $26 \cdot 9,112$ & $31 \cdot 3^{\star \star \star}$ & $15 \cdot 2,64 \cdot 4$ \\
\hline Soft drinks consumption (>65 ml/d) & $1 \cdot 92^{\star \star}$ & $1 \cdot 19,3 \cdot 11$ & $1 \cdot 82^{\star}$ & $1 \cdot 11,3 \cdot 00$ \\
\hline Water consumption $(>286 \mathrm{ml} / \mathrm{d})$ & $1 \cdot 04$ & $0.63,1.73$ & 0.93 & $0.55,1.55$ \\
\hline Milk products consumption $(>329 \mathrm{ml} / \mathrm{d})$ & 1.08 & $0.61,1.90$ & 1.04 & $0.60,1 \cdot 80$ \\
\hline Fruit consumption $(>136 \mathrm{~g} / \mathrm{d})$ & 0.98 & $0.59,1.64$ & $0 \cdot 85$ & $0.48,1.51$ \\
\hline Vegetable consumption ( $>72 \mathrm{~g} / \mathrm{d})$ & 1.05 & $0.55,2.03$ & $1 \cdot 30$ & $0 \cdot 74,2 \cdot 29$ \\
\hline Sweet and savoury snacks consumption ( $>54 \mathrm{~g} / \mathrm{d}$ ) & 0.92 & $0.47,1.79$ & $0 \cdot 76$ & $0.41,1 \cdot 40$ \\
\hline $\mathrm{PA}$ at home ( $>6 \mathrm{~h} /$ week $)$ & 0.96 & $0.60,1.53$ & 0.73 & $0.45,1 \cdot 16$ \\
\hline Structured PA ( $>3 \mathrm{~h} /$ week) & $1 \cdot 12$ & $0 \cdot 33,3.83$ & $1 \cdot 14$ & $0.57,3.51$ \\
\hline Screen time on weekdays $(>1 \mathrm{~h} / \mathrm{d})$ & $1 \cdot 23$ & $0.63,2.42$ & 1.57 & $0 \cdot 78,3 \cdot 14$ \\
\hline Screen time on weekend days $(>2 \mathrm{~h} / \mathrm{d})$ & $1 \cdot 10$ & $0 \cdot 55,2 \cdot 20$ & 1.05 & $0.49,1.50$ \\
\hline
\end{tabular}

${ }^{\star} P \leq 0.05,{ }^{* \star} P \leq 0.01,{ }^{* \star \star} P \leq 0.001$

that only soft drinks consumption was a risk factor: children who consumed more than $65 \mathrm{ml} / \mathrm{d}$ had more chance of being overweight at both follow-up measurements (first follow-up: $\mathrm{OR}=1 \cdot 92,95 \% \mathrm{CI} 1 \cdot 19,3 \cdot 11, P=0 \cdot 008$; second follow-up: $\mathrm{OR}=1 \cdot 82,95 \% \mathrm{CI} 1 \cdot 11,3 \cdot 00, P=0 \cdot 02)$. The other behavioural variables showed no significances.

\section{Discussion}

The present results show that $19 \%$ of the children were already overweight at the start of the study. This is in line with the general prevalence in European developed countries ${ }^{(44)}$. Five per cent of the children developed overweight during the study. This is a relatively small number and it cannot be excluded that potential risk factors were not significant due to lack of power. Consumption characteristics at baseline were in line with those found in earlier studies in Flanders on the same age group ${ }^{(45)}$.

The present study aimed to reveal risk factors for the development of childhood obesity on the familial, sociodemographic and behavioural domains and revealed several significant risk factors. Confirming earlier longitudinal studies, parental weight statuses were very important significant risk factors for the child's weight status. Parental overweight affects the child's weight status through complex mechanisms: there is a clear genetic predisposition and a food environmental aspect ${ }^{(7,8)}$. Parents have specific practices, styles and beliefs, and are in charge of the type and amount of food served. This finding implicates that interventions should target parental behaviour as well as the child's behaviour practices, styles and beliefs.

We also found maternal educational level to be a significant risk factor for childhood overweight. Previous studies used maternal educational level as an indicator for SES. Our study confirmed earlier findings for SES through this indicator: children of mothers without a higher education more frequently developed overweight. Earlier studies found this association at the cross-sectional level for the same age group ${ }^{(16)}$. Children of mothers with a low education have a higher risk of being overweight ${ }^{(18)}$. Possibly the same mechanism plays a role in the relationship between maternal educational level and overweight of the child as in the relationship between maternal overweight and the child's overweight. We did not find any significance for the other sociodemographic indicators such as paternal educational level, maternal and paternal professional status and language spoken at home. When maternal professional status was analysed in the same model as (and therefore controlled for) maternal educational level, the results showed that the risk factor for childhood overweight is the educational level of the mother, irrespective of the mother's professional status. This could imply that previous studies that found effects of the risk of maternal employment, such as the study of Wijga et al. ${ }^{(20)}$ and Anderson et al. ${ }^{(21)}$, could be interpreted as the results of the underlying maternal educational level: educational level can partly explain professional status and the hours the mother is obliged to work $^{(20,21,46)}$.

Being an only child was shown to be a risk factor for childhood overweight. This reveals the importance of family structure for the child. Children without siblings are more at risk of being overweight than children with siblings, even when controlling for other variables in our model such as living situation, PA and sedentary behaviour. Although some previous studies did not found an association between weight status and family composition ${ }^{(47)}$, Padez et al. ${ }^{(7)}$ also found in their cross-sectional study among 7- to 9.5-year-old children that being a single child was significantly associated with overweight in girls. This has also been reported in the past for the $\mathrm{UK}^{(48)}$, the Netherlands ${ }^{(49)}$ and more recently by the IDEFICS Study (Identification and prevention of Dietaryand lifestyle-induced health Effects In Children and infantS) ${ }^{(50)}$ using data of eight European countries. Children without siblings possibly got less PA, had greater sugar consumption and were more likely to have a TV in their bedroom $^{(50)}$. This should be kept in mind when developing interventions addressing lifestyle behaviours. 
In the first model analysis with both unchangeable and changeable variables, screen time on weekdays was associated with the child's weight status. Children with more than $1 \mathrm{~h}$ of screen time on weekdays had greater chance of being overweight at the follow-up measurements, despite the inclusion and therefore controlling for the sociodemographic and behavioural variables in the model. Interventions focusing on decreasing screen time should address every child and the reduction of screen time should always be an important focus for interventions on the prevention of childhood overweight.

When the sociodemographic variables were excluded from the model, soft drinks consumption became significant as a risk factor. Children who drank more soft drinks had a higher chance of becoming overweight. This is consistent with earlier studies ${ }^{(25,26,51,52)}$. It is already known that low-SES children consume significantly more soft drinks ${ }^{(53)}$. This is important for interventions on the prevention of childhood overweight with a focus on soft drinks consumption: they should focus on the soft drinks consumption in a more complex combination of environmental and behavioural strategies and customize the intervention for high-risk groups, such as low-SES families. No other behavioural variables were shown to be a significant risk factor for childhood overweight.

The present study has important implications for future interventions: it identified risk factors, showing the importance of parental weight and family structure on the child's weight status. Future interventions should not solely address the child but the whole family and lifestyle, especially high-risk groups such as low-SES families, and pay special attention to screen time and soft drinks consumption.

\section{Strengths and limitations}

The current 30-month longitudinal study was conducted among an understudied age group of 3- to 6-year-olds. This age range is crucial: the critical moment when adiposity rebound occurs ${ }^{(14)}$ and it is a favourable time for prevention and interventions. The results gave an insight into the risk factors for developing overweight and the influence of sociodemographic and behavioural variables. A validated FFQ estimated the consumption behaviour. Weight and height of the children (for BMI) were objectively measured by the same team by the same measurement protocol.

However, there are some limitations to consider. There was a baseline non-response rate of $52.5 \%$. Some questions in the questionnaires were left blank. The collected data may not be representative. Most data for the variables (with the exception of the child's weight status) were self-reported; therefore social desirability cannot be excluded. Only $5 \%$ of the children developed overweight during the study. It is possible that this sample is too small to reveal all relevant risk factors. Future research with longitudinal studies over a longer period of time among a larger sample is required.

\section{Acknowledgements}

Sources of funding: The study was commissioned, financed and steered by the Ministry of the Flemish Community (Department of Economics, Science and Innovation; Department of Welfare, Public Health and Family). The work was performed by the Centre of Expertise for Welfare, Public Health and Family. This is a consortium of researchers of the Catholic University of Leuven (KU Leuven), Ghent University (UGent), Vrije Universiteit Brussel (VUB) and Katholieke Hogeschool Kempen (KhK). The Ministry of the Flemish Community had no role in the design, analysis or writing of this article. Conflicts of interest: There are no conflicts of interest. Authorship: L.M., I.D.B. and V.D.C. conceived the outline for the study design. Data were collected by L.M. and V.D.C. V.D.C. carried out the literature search and analysed the data. Data were interpreted by all the authors. All authors were involved in writing the paper and had final approval of the submitted version.

\section{References}

1. Wang $\mathrm{Y}$ \& Lobstein $\mathrm{T}$ (2006) Worldwide trends in childhood overweight and obesity. Int J Pediatr Obes $\mathbf{1}$, $11-25$.

2. de Onis M, Blössner M \& Borghi E (2010) Global prevalence and trends of overweight and obesity among preschool children. Am J Clin Nutr 92, 1254-1264.

3. Gutin B, Basch C, Shea S et al. (1990) Blood pressure, fitness, and fatness in 5- and 6-year-old children. JAMA 264, 1123-1127.

4. Ehtisham S \& Barrett TG (2004) The emergence of type 2 diabetes in childhood. Ann Clin Biochem 41, 10-16.

5. Friedlander SL, Larkin EK, Rosen CL et al. (2003) Decreased quality of life associated with obesity in school-aged children. Arch Pediatr Adolesc Med 157, 1206-1211.

6. Reilly JJ \& Kelly J (2011) Long-term impact of overweight and obesity in childhood and adolescence on morbidity and premature mortality in adulthood: systematic review. Int J Obes (Lond) 35, 891-898.

7. Padez C, Mourao I, Moreira P et al. (2005) Prevalence and risk factors for overweight and obesity in Portuguese children. Acta Paediatr 94, 1550-1557.

8. Maffeis C (2000) Aetiology of overweight and obesity in children and adolescents. Eur J Pediatr 159, Suppl. 1, S35-S44.

9. Svensson V, Jacobsson JA, Fredriksson R et al. (2011) Associations between severity of obesity in childhood and adolescence, obesity onset and parental BMI: a longitudinal cohort study. Int J Obes (Lond) 35, 46-52.

10. Danielzik S, Czerwinski-Mast M, Langnase K et al. (2004) Parental overweight, socioeconomic status and high birth weight are the major determinants of overweight and obesity in 5-7 y-old children: baseline data of the Kiel Obesity Prevention Study (KOPS). Int J Obes (Lond) 28, 1494-1502.

11. Laitinen J, Power C \& Järvelin M (2001) Family social class, maternal body mass index, childhood body mass index, and age at menarche as predictors for adult obesity. $A m J$ Clin Nutr 74, 287-294.

12. Lake JK, Power C \& Cole TJ (1997) Child to adult body mass index in the 1958 British birth cohort: associations with parental obesity. Arch Dis Child 77, 376-381. 
13. Maffeis C, Talamini G \& Tato L (1998) Influence of diet, physical activity and parents' obesity on childrens' adiposity: a four-year longitudinal study. Int J Obes Relat Metab Disord 22, 758-764.

14. Hui LL, Nelson EA, Yu LM et al. (2003) Risk factors for childhood overweight in 6- to 7-y-old Hong Kong children. Int J Obes Relat Metab Disord 27, 1411-1418.

15. Scaglioni S, Agostini C, De Notaris R et al. (2000) Early macronutrient intake and overweight at five years of age. Int J Obes Relat Metab Disord 24, 777-781.

16. Lamerz A, Kuepper-Nybelen J, Wehle C et al. (2005) Social class, parental education, and obesity prevalence in a study of six-year-old children in Germany. Int J Obes (Lond) 29, 373-380.

17. Blair NJ, Thompson JM, Black PN et al. (2007) Risk factors for obesity in 7-year-old European children: the Auckland Birthweight Collaborative Study. Arch Dis Child 92, 866-871.

18. Semmler C, Ashcroft J, van Jaarsveld $\mathrm{CH}$ et al. (2009) Development of overweight in children in relation to parental weight and socioeconomic status. Obesity (Silver Spring) 17, 814-820.

19. Singh AS, Mulder C, Twisk JW et al. (2008) Tracking of childhood overweight into adulthood: a systematic review of the literature. Obes Rev 9, 474-488.

20. Wijga AH, Scholtens S, Bemelmans WJ et al. (2010) Diet, screen time, physical activity, and childhood overweight in the general population and in high risk subgroups: prospective analyses in the PIAMA birth cohort. $J$ Obes 2010, 423296.

21. Anderson PM, Butcher KF \& Levine PB (2003) Maternal employment and overweight children. J Health Econ 22, 477-504.

22. Langnase K, Mast M \& Muller MJ (2002) Social class differences in overweight of prepubertal children in northwest Germany. Int J Obes Relat Metab Disord 26, 566-572.

23. Agostini C, Braegger C, Decsi T et al. (2011) Role of dietary factors and food habbits in the development of childhood obesity: a commentary by the ESPGHAN committee on nutrition. J Pediatr Gastroenterol Nutr 52, 662-669.

24. Vartanian LR, Schwartz MB \& Brownell KD (2007) Effects of soft drink consumption on nutrition and health: a systematic review and meta-analysis. Am J Public Health 97, 667-675.

25. Welsh JA, Cogswell ME, Rogers S et al. (2005) Overweight among low-income preschool children associated with the consumption of sweet drinks: Missouri, 1999-2002. Pediatrics 115, E223-E229.

26. Moreno LA \& Rodriguez G (2007) Dietary risk factors for development of childhood obesity. Curr Opin Clin Nutr Metab Care 10, 336-341.

27. Field AE, Austin SB, Gillman MW et al. (2004) Snack food intake does not predict weight change among children and adolescents. Int J Obes Relat Metab Disord 28, 1210-1216.

28. Epstein LH, Gordy CC, Raynor HA et al. (2001) Increasing fruit and vegetable intake and decreasing fat and sugar intake in families at risk for childhood obesity. Obes Res $\mathbf{9}$, 171-178.

29. Lin B \& Morrison M (2002) Higher fruit consumption linked with lower body mass index. Food Rev 25, 28-32.

30. Field AE, Gillman MW, Rosner B et al. (2003) Association between fruit and vegetable intake and change in body mass index among a large sample of children and adolescents in the United States. Int J Obes Relat Metab Disord 27, 821-826.

31. Skinner JD, Bounds W, Carruth BR et al. (2003) Longitudinal calcium intake is negatively related to the children's body fat indexes. J Am Diet Assoc 103, 1626-1631.

32. Jimenez-Pavon D, Kelly J \& Reilly JJ (2010) Associations between objectively measured habitual physical activity and adiposity in children and adolescents: systematic review. Int J Pediatr Obes 5, 3-18.

33. Must A \& Tybor DJ (2005) Physical activity and sedentary behavior: a review of longitudinal studies of weight and adiposity in youth. Int J Obes (Lond) 29, Suppl. 2, S84-S96.

34. LeBlanc MM, Martin CK, Han H et al. (2012) Adiposity and physical activity are not related to academic achievement in school-aged children. J Dev Behav Pediatr 33, 486-494.

35. Timmons BW, Proudfoot NA, MacDonald MJ et al. (2012) The health outcomes and physical activity in preschoolers (HOPP) study: rationale and design. BMC Public Health 12, 284.

36. Jago R, Baranowski T, Baranowski JC et al. (2005) BMI from 3-6y of age is predicted by TV viewing and physical activity, not diet. Int J Obes (Lond) 29, 557-564.

37. Hesketh K, Carlin J, Wake M et al. (2009) Predictors of body mass index change in Australian primary school children. Int J Pediatr Obes 4, 45-53.

38. Cole TJ (1990) The LMS method for constructing normalized growth standards. Eur J Clin Nutr 44, 45-60.

39. Roelants M, Hauspie R \& Hoppenbrouwers K (2009) References for growth and pubertal development from birth to 21 years in Flanders, Belgium. Ann Hum Biol 36, 680-694.

40. Huybrechts I, De Backer G, De Bacquer D et al. (2009) Relative validity and reproducibility of a food-frequency questionnaire for estimating food intakes among Flemish preschoolers. Int J Environ Res Public Health 6, 382-399.

41. Kohl HW, Fulton JE \& Caspersen CJ (2000) Assessment of physical activity among children and adolescents: a review and synthesis. Prev Med 31, issue 2, S54-S76.

42. Sallis JF, Condon SA, Goggin KJ et al. (1993) The development of self-administered physical activity surveys for 4th grade students. Res Q Exerc Sport 64, 25-31.

43. Kuczmarski RJ, Ogden CL, Guo S et al. (2002) 2000 CDC Growth charts for the United States: methods and development. Vital Health Stat 246, 1-190.

44. Lobstein T \& Jackson-Leach R (2006) Estimated burden of paediatric obesity and co-morbidities in Europe. Part 2. Numbers of children with indicators of obesity-related disease. Int J Pediatr Obes 1, 33-41.

45. Huybrechts I, Matthys C, Vereecken C et al. (2008) Food intakes by preschool children in Flanders compared with dietary guidelines. Int J Environ Res Public Health 5, 243-257.

46. Hawkins SS, Cole TJ \& Law C (2008) Maternal employment and early childhood overweight: findings from the UK Millennium Cohort Study. Int J Obes (Lond) 32, 30-38.

47. Reilly JJ, Armstrong J, Dorosty AR et al. (2005) Early life risk factors for obesity in childhood: cohort study. BMJ 330, 1357.

48. Whitelaw AG (1971) The association of social class and sibling number with skinfold thickness in London schoolboys. Hum Biol 43, 414-420.

49. Ravelli GP \& Belmont L (1979) Obesity in nineteen-yearold men: family size and birth order associations. Am J Epidemiol 109, 66-70.

50. Hunsberger M, Formisano A, Reisch LA et al. (2012) Overweight in singletons compared to children with siblings: the IDEFICS study. Nutr Diabetes 2, e56.

51. Libuda L \& Kersting M (2009) Soft drinks and body weight development in childhood: is there a relationship? Curr Opin Clin Nutr Metab Care 12, 596-600.

52. Warner ML, Harley K, Bradman A et al. (2006) Soda consumption and overweight status of 2-year-old MexicanAmerican children in california. Obesity (Silver Spring) 14, 1966-1974.

53. De Coen V, Vansteelandt S, Maes L et al. (2012) Parental socioeconomic status and soft drink consumption of the child. The mediating proportion of parenting practices. Appetite 59, 76-80. 